\title{
Visible, near-infrared, and mid-infrared spectral characterization of Hawaiian fumarolic alteration near Kilauea's December 1974 flow: Implications for spectral discrimination of alteration environments on Mars
}

\author{
Marcella YAnT ${ }^{1, *} \uparrow$, Kelsey E. Young ${ }^{2}$, A. Deanne Rogers ${ }^{1}$, Amy C. MCAdAM $^{2}$, \\ JACOB E. Bleacher ${ }^{2}$, JANice L. Bishop ${ }^{3}$, AND Stanley A. MertzMaN ${ }^{4}$ \\ ${ }^{1}$ Department of Geosciences, Stony Brook University, Stony Brook, New York, U.S.A. \\ ${ }^{2}$ NASA Goddard Space Flight Center, Greenbelt, Maryland, U.S.A. \\ ${ }^{3}$ SETI Institute, Mountain View, California, U.S.A. \\ ${ }^{4}$ Earth and Environmental Department, Franklin and Marshall College, Lancaster, Pennsylvania, U.S.A.
}

\begin{abstract}
The December 1974 flow in the SW rift zone at Kilauea Volcano, Hawaii, has been established as a Mars analog due to its physical, chemical, and morphological properties, as well as its interaction with the outgassing plume from the primary Kilauea caldera. We focus on a solfatara site that consists of hydrothermally altered basalt and alteration products deposited in and around a passively degassing volcanic vent situated directly adjacent to the December 1974 flow on its northwest side. Reflectance spectra are acquired in the visible/near-infrared (VNIR) region and emission spectra in the mid-infrared (MIR) range to better understand the spectral properties of hydrothermally altered materials. The VNIR signatures are consistent with silica, Fe-oxides, and sulfates ( $\mathrm{Ca}, \mathrm{Fe})$. Primarily silica-dominated spectral signatures are observed in the MIR and changes in spectral features between samples appear to be driven by grain size effects in this wavelength range. The nature of the sample coating and the thermal emission signatures exhibit variations that may be correlated with distance from the vent. Chemical analyses indicate that most surfaces are characterized by silica-rich material, Fe-oxides, and sulfates $(\mathrm{Ca}, \mathrm{Fe})$. The silica and Fe-oxide-dominated MIR/VNIR spectral signatures exhibited by the hydrothermally altered material in this study are distinct from the sulfate-dominated spectral signatures exhibited by previously studied low-temperature aqueous acid-sulfate weathered basaltic glass. This likely reflects a difference in open vs. closed system weathering, where mobile cations are removed from the altered surfaces in the fumarolic setting. This work provides a unique infrared spectral library that includes martian analog materials that were altered in an active terrestrial solfatara (hydrothermal) setting. Hydrothermal environments are of particular interest as they potentially indicate habitable conditions. Key constraints on the habitability and astrobiological potential of ancient aqueous environments are provided through detection and interpretation of secondary mineral assemblages; thus, spectral detection of fumarolic alteration assemblages observed from this study on Mars would suggest a region that could have hosted a habitable environment.
\end{abstract}

Keywords: Glass, infrared, Mars, Hawaii; Earth Analogs for Martian Geological Materials and Processes 

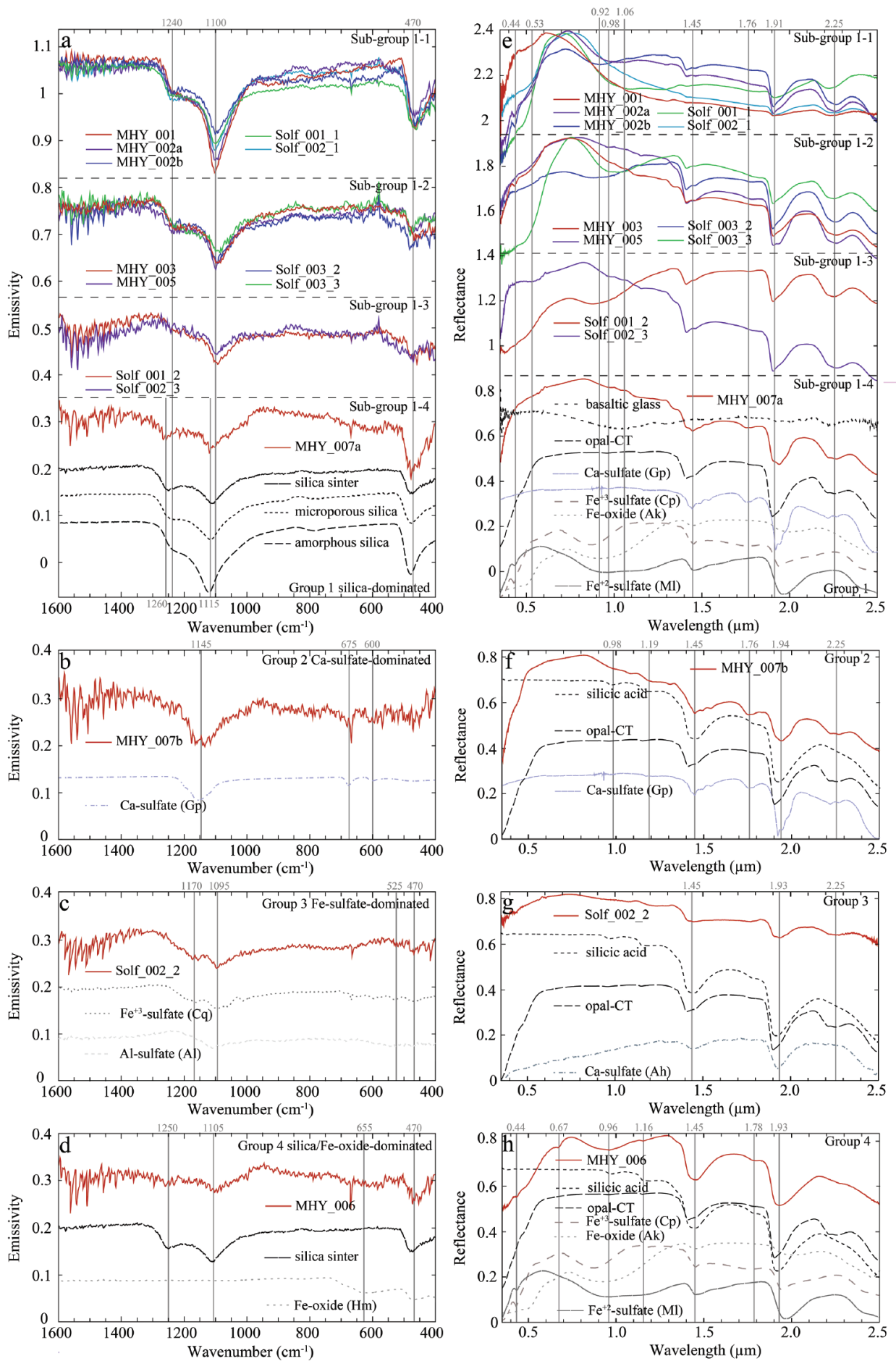

FIGURE 2. Thermal emission signatures of the collected samples grouped based on similarities of dominant spectral features into (a) Group 1, silica-dominated, (b) Group 2, Ca-sulfate-dominated, (c) Group 3, Fe-sulfate-dominated, and (d) Group 4 (silica/Fe-oxide-dominated). The reflectance spectra are separated into groups based on the MIR groups established in panels a-d, (e) Group 1, (f) Group 2, (g) Group 3, and (h) Group 4. Vertical lines indicate features discussed in text. The spectra have been offset along the $\mathrm{y}$-axis for clarity. $\mathrm{Gp}=$ gypsum, $\mathrm{Ah}=$ anhydrite, $\mathrm{Ak}=\mathrm{akaganéite}$, $\mathrm{Ml}=$ melanterite, $\mathrm{Al}=$ alunogen, $\mathrm{Cq}=$ coquimbite, $\mathrm{Hm}=$ hematite. The library spectra used here were not measured in this study and include silica sinter, microporous silica, amorphous silica (Ruff et al. 2011), gypsum (Lane 2007), coquimbite (Lane et al. 2015), alunogen (Lane, unpublished), and hematite (Christensen et al. 2000) for the MIR. In the VNIR, the library spectra include basaltic glass (Yant et al. 2016), silicic acid, opal-CT (Rice et al. 2013), gypsum (RELAB ID: C1JB557), akaganéite (RELAB ID: 397F212D), melanterite (RELAB ID: CASF44), copiapite (RELAB ID: C1JBA51), and anhydrite (RELAB ID: C1JB641A). (Color online.) 
als, however, based on the shape of the features near $0.98,1.19$, 1.4 , and $1.9 \mu \mathrm{m}$, these spectral bands may indicate the presence of hydrated silica in our samples.

In general, the features present in the reflectance spectra are similar within the groups of samples, however there are some variations. In Group 1-1, the spectra exhibited deep silica features in the MIR. Although influence from silica is observed for all five samples in the VNIR, a broad absorption in the $0.92-1.06 \mu \mathrm{m}$ range is also exhibited, consistent with $\mathrm{Fe}^{2+}$-sulfate (melanterite) and/or Fe-oxide (akaganéite), or perhaps an iron impurity within the silica phase or mineral mixing (Fig. 2e). The shoulder near $0.53 \mu \mathrm{m}$ observed for HI_15_MHY_001 and Solf_002_1 may also indicate influence from Fe-oxides. Overall, $\mathrm{MHY}$ 001, Solf_001_1, and Solf_002_1 display shallow features consistent with basaltic glass along with some influence from opal-CT near 1.91 and $2.25 \mu \mathrm{m}$, whereas MHY 002a and MHY 002b exhibit deeper features primarily consistent with opal-CT. Additionally, MHY 001 and Solf 002 1 exhibit negative spectral slopes and a concave nature, possibly due to thin coatings and/or fine grain size (e.g., Fischer and Pieters 1993) or due to acidic leaching of glass (Horgan and Bell 2012). Group 1-2 exhibited shallowed silica features in the MIR. Again all of the VNIR spectra in this group are consistent with the presence of silica, however all of these samples also exhibit influence from Fe-oxide (akaganéite) and/or trace iron impurity, near $0.44,0.53$, and/or $0.98 \mu \mathrm{m}$ (Fig. 2e). The feature near 0.44 could also be due to the presence of $\mathrm{Fe}^{2+}$-sulfate (melanterite) and/or $\mathrm{Fe}^{3+}$-sulfate (copiapite or jarosite). The features observed near $1.45,1.91$, and $2.25 \mu \mathrm{m}$ for the samples in this group are consistent with opal-CT.

The MIR signatures for Group 1-3 were silica-dominated, but with severe shallowing of the $1240 \mathrm{~cm}^{-1}$ feature. The VNIR signatures for both samples in this group are influenced by silica, exhibiting features consistent with opal-CT $(1.45,1.91$, $2.25 \mu \mathrm{m}$ ) (Fig. 2e). Both samples included in this group also display features that may be due to the presence of Fe-oxide (akaganéite), near 0.53 and $0.98 \mu \mathrm{m}$. The shifted silica features observed for Group 1-4 in the MIR correspond with a VNIR signature dominated by silica and Ca-sulfate (Fig. 2e). The shape of the feature near $1.45 \mu \mathrm{m}$ is most consistent with Ca-sulfate (gypsum) along with the absorption near $1.76 \mu \mathrm{m}$. The feature near $2.25 \mu \mathrm{m}$ is most consistent with opal-CT. Group 2 is Casulfate-dominated in the MIR, and exhibits features dominated by Ca sulfate (gypsum, near 1.45, 1.76, and $1.94 \mu \mathrm{m}$ ) with some influence from silica near $2.25 \mu \mathrm{m}$ and silicic acid near 0.98 and $1.19 \mu \mathrm{m}$ (Fig. 2f). The reflectance features of the Group 3 spectrum are consistent with Ca-sulfate (gypsum or bassanite, near 1.45 and $1.93 \mu \mathrm{m}$ ) in the VNIR with opal likely as well due to the broadness of these bands, lack of $1.76 \mu \mathrm{m}$ feature, and the presence of a feature near $2.25 \mu \mathrm{m}$ (Fig. 2g). The last group exhibits influence from silica and Fe-oxide in the MIR. The reflectance signature for Group 4 is also consistent with adsorbed water bands observed for hydrated silica (1.16, 1.45, 1.76, and $1.93 \mu \mathrm{m}$ ) and Fe-oxide (near $0.96 \mu \mathrm{m}$ ). Akaganéite provided the best match from the Fe-oxide library spectra used in this study, as it contains characteristic $\mathrm{Fe}^{3+}$ absorptions near 0.44 , 0.59 (shoulder), and $0.92 \mu \mathrm{m}$ (Bishop et al. 2015); however, we did not observe the expected $\mathrm{H}_{2} \mathrm{O}$ band near 1.95-2.0 $\mu \mathrm{m}$ or $\mathrm{OH}$ band near $2.46 \mu \mathrm{m}$, so akaganéite cannot be a dominant component. This sample also may display influence from $\mathrm{Fe}^{2+}$ sulfate (melanterite) and/or $\mathrm{Fe}^{3+}$-sulfate (copiapite, jarosite) near $0.44 \mu \mathrm{m}$ (Fig. 2h).

Linear least-squares analysis was used to model the averaged thermal emission spectra for each group. A full table of the modeling results is available in the Supplementary ${ }^{1}$ Material (SI 1). The phases listed as minor are below the detection limits of this method and may not be present. The MIR Group 1-1 also had a silica-dominated modeled assemblage, but lower amounts of sulfate and minor Fe-oxide were used by the model to improve the fit (Fig. 3a). The shallowed silica features exhibited by MIR Group 1-2 also resulted in a silica-dominated modeled assemblage, but with influence from sulfate, clay (montmorillonite, Fe/Al-smectite), and minor sulfur (Fig. 3b). The relatively poor fits for Groups 1-3 and 1-4 indicate non-linear mixing likely due to small particle sizes, and poorly crystalline components. An $\mathrm{Fe}^{3+}$-sulfate-Al-sulfate-dominated modeled assemblage (Fig. 3c) was observed for Group 1-3, contrasting the silica-dominated grouping. The shifted silica features observed for MIR Group 1-4 still produced a silica-dominated modeled assemblage, but with influence from Fe-oxide and sulfur (Fig. 3d). The modeled spectrum for MIR Group 2 resulted in a Ca-sulfate-dominated assemblage with influence from silica (Fig. 3e). The $\mathrm{Fe}^{3+}$ sulfate-dominated model fit for MIR Group 3 is relatively poor, as with Groups 1-3 and 1-4 and is likely influenced by particle size effects (Fig. 3f). Last, the modeled assemblage for the MIR Group 4 is dominated by silica and Fe-oxide with influence from sulfate (Fig. 3g), consistent with the silica/Fe-oxide-dominated grouping.

\section{Chemical and mineralogical analyses}

SEM analyses were only acquired for the HI_15_MHY samples and thus only these samples are discussed (no data was collected for Group 1-3 or Group 3) using secondary electron images. The Group 1-1 samples all exhibit similar silica-dominated surfaces (Figs. 4a-4c). The surface of HI_15_MHY_001 is characterized by a Si-rich leached coating, overlying a glass with considerable Al, Ca, Mg, and Fe (Fig. 4a). HI_15_MHY_002a is also dominated by a Si-rich coating (Fig. 4b), with some Fe-sulfates and Ca-sulfates observed sparsely. A Si-Ti-Fe-rich surface coating is also observed, but is not as pervasive as the Si-rich surface. A Si-rich surface is also observed for HI_15_MHY_002b, overlying a glass similar to that observed for $\mathrm{HI}_{-} 15$ _ MHY_001 (Fig. 4c). The samples from Group 1-2 also exhibit a Si-rich coating, but are consistent with other materials (Figs. 4d-4e). HI_15_MHY_003 has a Si-rich surface, with Ca-sulfate present in some areas (Fig. 4d). HI_15_MHY_005 has a Si-rich surface with Fe-Ti-oxides and Ca-sulfate deposited on top (Fig. 4e). The surface of the only sample from Group 1-4, HI_15_MHY_007a, is characterized by Si-rich material and Ca-sulfate (Fig. 4f). With Group 2, the surfaces are less dominated by silica compared to Group 1.HI_15_MHY_007b exhibits centimeter-sized clasts of Si-rich material (Fig. 4g) and Ca-sulfates (Fig. 4h). For Group 4, the surface of HI 15 MHY 006 is characterized by Si-rich material overlain considerably by Fe-Ti-oxides (Fig. 4i).

The results from the XRD analyses are listed in Table 2. Generally, amorphous material \pm crystalline silica was observed for all of these samples. The amorphous material could indicate 

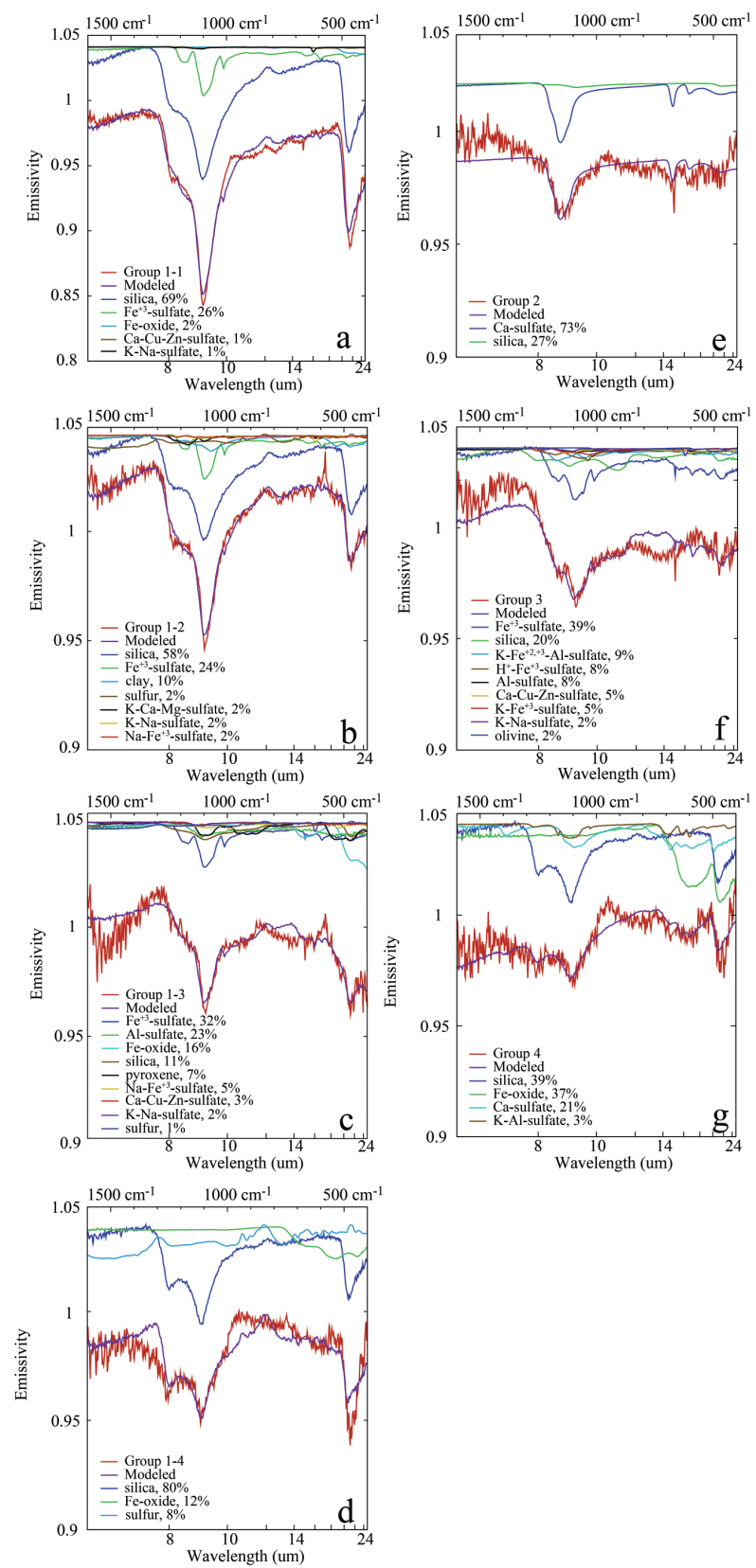

FIGURE 3. Linear least-squares analysis models for the average thermal emission spectrum for each group: (a) Group 1-1, (b) Group 1-2, (c) Group 1-3, (d) Group 1-4, (e) Group 2, (f) Group 3, and (g) Group 4. The y-axis has been offset for clarity. (Color online.)

glass, silica, allophane, imogolite, or other amorphous materials that result in a characteristic hump in the XRD pattern. Crystalline silica is referring to crystalline polymorphs of $\mathrm{SiO}_{2}$ (e.g., tridymite and cristobalite), which have distinct XRD peaks. Small amounts of additional phases were observed for Group 1-2 (blixite, Fe-oxides, zeolites, and K-sulfate), Group 1-3 (Feoxides), and Group 2 (Ca-sulfate, sulfur). The XRD patterns for all of these samples exhibited broad features consistent with an amorphous material such as amorphous silica, allophane, and/or basaltic glass. For three samples, the broad diffraction hump had a width of $\sim 16^{\circ} 2 \theta$ and the center was shifted to lower ${ }^{\circ} 2 \theta$ values $\left(\sim 23^{\circ} 2 \theta\right)$, indicating material that is more Si rich than pure basaltic glass (Fig. 5). No halite was observed in these samples.

The XRF data has been separated into three groups based on chemical similarities determined using a minimum distance clustering algorithm on handheld XRF chemical data for each sample (Fig. 6a). This independent XRF-based grouping was done to compare how/if element-based compositional variability corresponds with spectrally determined variability. Chemical variations are most strongly driven by abundances of $\mathrm{Si}, \mathrm{Fe}$, and less so by $\mathrm{Al}$ and $\mathrm{Ca}$. The abundance of $\mathrm{Si}$ is negatively correlated with $\mathrm{Fe}, \mathrm{Al}$, and $\mathrm{Ca}$. The XRF Group 1 consists of samples HI_15_Solf_002_3 (MIR Group 1-3) and HI_15_Solf_003_2 (MIR Group 1-2) and displays relatively higher enrichment in $\mathrm{Si}$ and lower enrichment in $\mathrm{Ca}$ and $\mathrm{Fe}$ compared to the other groups. XRF Group 2 exhibits medium enrichment in $\mathrm{Si}, \mathrm{Fe}, \mathrm{Al}$, and $\mathrm{Ca}$ and includes samples from MIR Group 1-1 (HI 15 MHY 001, HI 15 MHY 002a), Group 1-2 (HI 15 M $\mathrm{M} H \bar{Y}$ 003, HI 15 MHY 005, $\overline{\mathrm{HI}} 15$

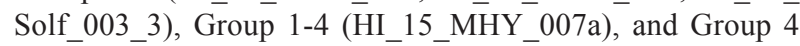
(HI_15_MHY_006). The XRF Group 3 includes samples from MIR Group 1-1 (HI_15_Solf_001_1, HI_15_Solf_002_1), Group 1-3 (HI 15 Solf $001 \overline{2}$ ), and Group 3 ( $\overline{\mathrm{HI}} \overline{15}$ Solf 002 2) that display relatively low enrichment in $\mathrm{Si}$ and high enrichment in $\mathrm{Al}, \mathrm{Ca}$, and $\mathrm{Fe}$. The $\mathrm{Al}$ vs. Si and Fe vs. Si plots (Figs. 6b-6c) display the negative correlations that were observed by the minimum distance clustering. These plots also indicate that the XRF compositional groupings of samples are not the same as the previous MIR groups, although there are some similarities.

\section{DISCUSSION}

\section{Spectral detectability}

Overall, the surfaces of the hydrothermally altered samples analyzed here are characterized by silica-rich material \pm Fe-oxides and $\mathrm{Ca}$-sulfate, based on chemical and mineralogical analyses (Table 2). Several XRD patterns exhibited amorphous humps centered near $24^{\circ} 2 \theta$; this position is consistent with an amorphous material that is more Si rich than basaltic glass (Fig. 5). Silica-rich materials generally have a narrower hump centered at lower positions near $25^{\circ} 2 \theta$, whereas basaltic glass generally has a broader hump centered at higher positions, near $31^{\circ} 2 \theta$ (Morris et al. 2015). This is consistent with MIR/VNIR data that showed amorphous silica contributed to the spectral shape for all samples. Although both the MIR/VNIR and handheld XRF data are detecting strong enrichments in $\mathrm{Si}$ or Si-bearing phases, compositional groupings of samples using each technique are not well correlated. This could be due to the sensitivity of the handheld XRF to chemical changes vs. MIR/VNIR spectroscopy, which are sensitive to mineral species and abundance. Likewise, minor alteration phases observed on sample surfaces in SEM images are often not exhibited in the XRD data due to the small contribution of the surface material to the bulk sample.

In general, the dominant surface phases are clearly identified in the VNIR and MIR spectral signatures; however, for some samples, the spectral models include large abundances of phases that are absent in SEM data. For example, the surfaces of samples HI_15_MHY_001 and HI_15_MHY_002b (Group 

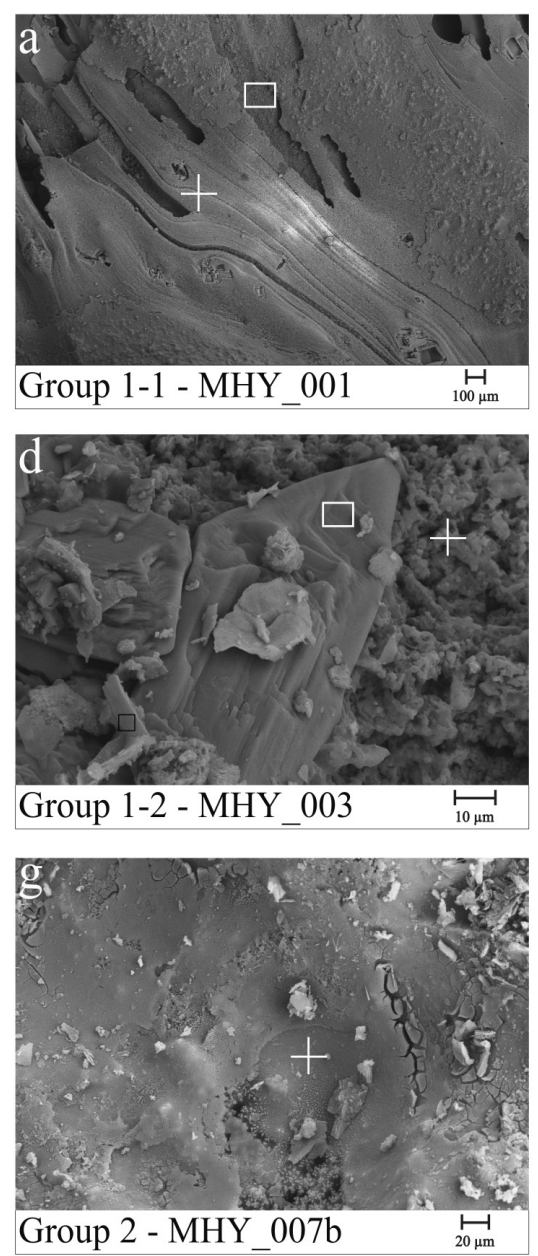
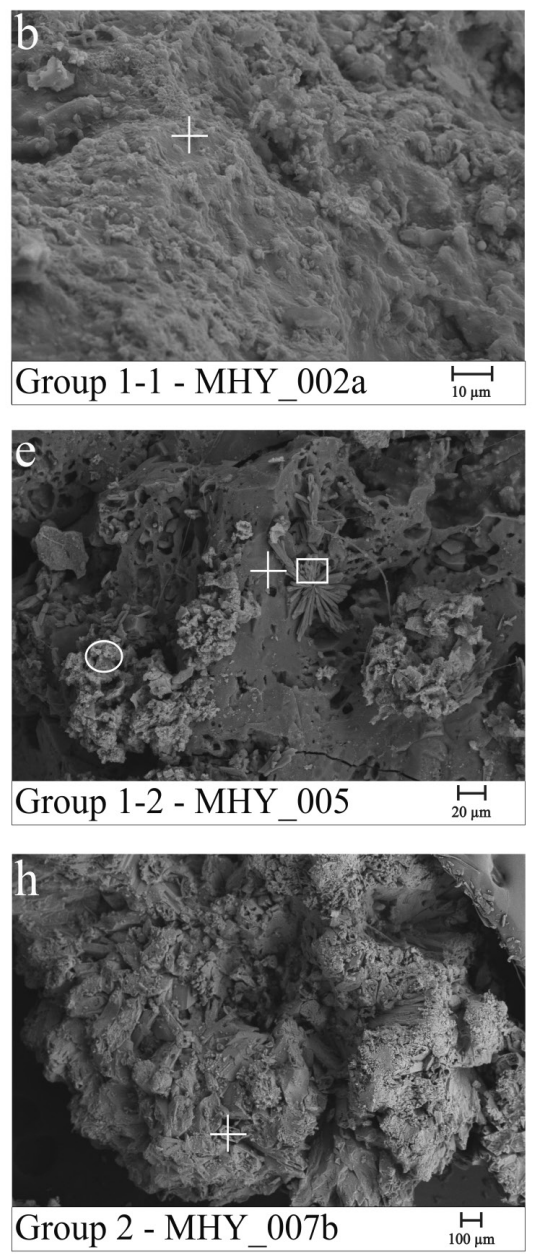
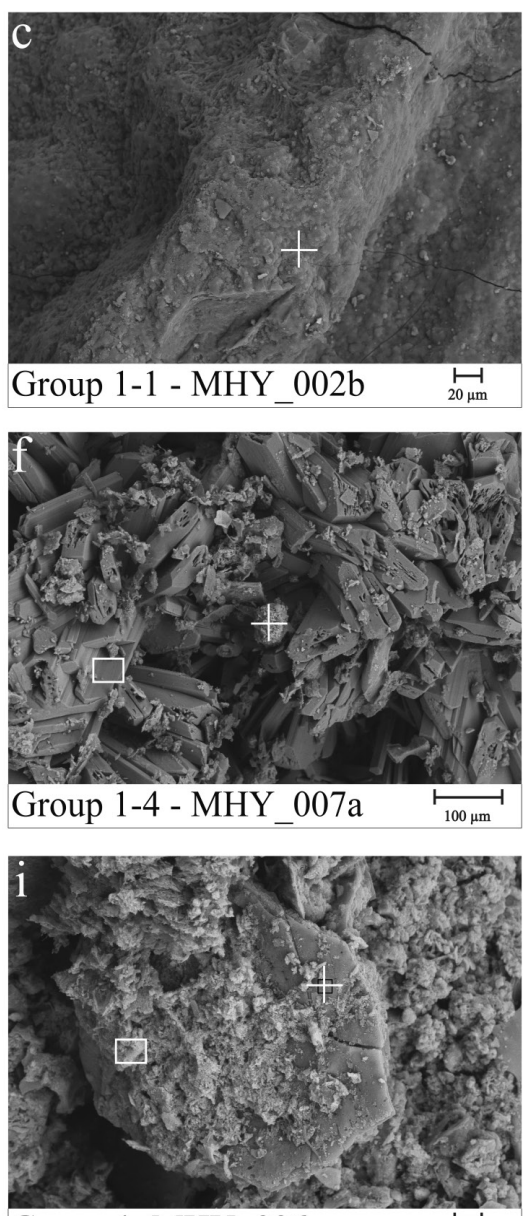

Group 4- MHY 006 $\stackrel{\mapsto}{\longmapsto}$

FIGURE 4. Secondary electron images of HI_15_MHY samples: Group 1-1: (a) HI_15_MHY 001 exhibiting a Si-rich coating (cross) overlying an Al, Ca, Mg, Fe-rich glass (square), (b) HI_15_M MHY_002a exhibiting a Si-rich surface (cross), and (c) HI_15_MHY_002b exhibiting a Si-rich coating (cross); Group 1-2: (d) HI_15_MHY_003 exhibiting Si-rich material (cross) and Ca-sulfate (square) and (e) HI_15_MHY_005 exhibiting Si-rich surface (cross), Ca-sulfate (square), Fe-Ti-oxide (circle); Group 1-4: (f) HI_15_MHY_007a exhibiting Si-rich material (cross) and Ca-sulfate (square); Group 2: HI_15_MHY_007b exhibiting (g) Si-rich clast and (h) Ca-sulfate rich clast; and Group 3: (i) HI_15_MHY_006 exhibiting Sirich material (cross) and Fe-Ti-oxide (square).

1-1) are both characterized by a silica coating based on SEM analysis (Figs. $4 \mathrm{a}$ and $4 \mathrm{c}$ ). However, in the MIR additional phases (sulfates and Fe-oxides) are needed to provide the best fit to the sample spectra (Fig. 3a). In addition, phyllosilicates (montmorillonite, Fe/Al-smectite) are included in the modeled assemblage for Group 1-2 (Fig. 3b) when none was observed on any of the sample surfaces. This phenomenon, as well as the poor fits to some of the modeled spectra (e.g., MIR Group 3), is likely due to the fine-grained nature of the weathered surfaces. Volume scattering and transmission through small grains or thin coatings can give rise to spectral features that are not well modeled by library spectra of pure, coarse-grained phases.

Differences in grain size also appear to be a major factor in the spectral differences between the samples in the MIR silica-dominated group (Group 1). SEM data was only collected for the HI_15_MHY samples and thus only these samples are discussed. The samples with the deepest features (Group 1-1; HI_15_MHY_001, 002a, and 002b) all have continuous silica coatings with little to no fine-grained surface material (Figs. $4 a-4 c)$. However, the samples with shallow silica features (Group 1-2 and 1-4; HI_15_MHY_003, 005, and 007a) have finer-grained surfaces (Figs. 4d-4f), and HI_15_MHY_005 and HI_15_MHY_007a also have numerous cavities. Additionally, the shallow silica features could be due to a relatively low abundance of silica-rich material due the presence of oxides and sulfates.

The variations observed between the subgroups of the silicadominated thermal emission spectra appear to be correlated with distance from the volcanic vent. The distance was only measured for the HI_15_MHY samples and thus only these are discussed. The purest silica features were exhibited by the material farthest from the vent (Group 1-1, 19.0-18.0 m) with shallowing of silica features in the intermediate material (Group 1-2, 11.5-4.7 m), and shifting of features in the material closer to the vent (Group $1-4,4.5 \mathrm{~m})$. The material collected closest to the vent exhibited sulfate-dominated features (Group 2, $4.5 \mathrm{~m}$ and Group 3, $4.0 \mathrm{~m}$ ). 

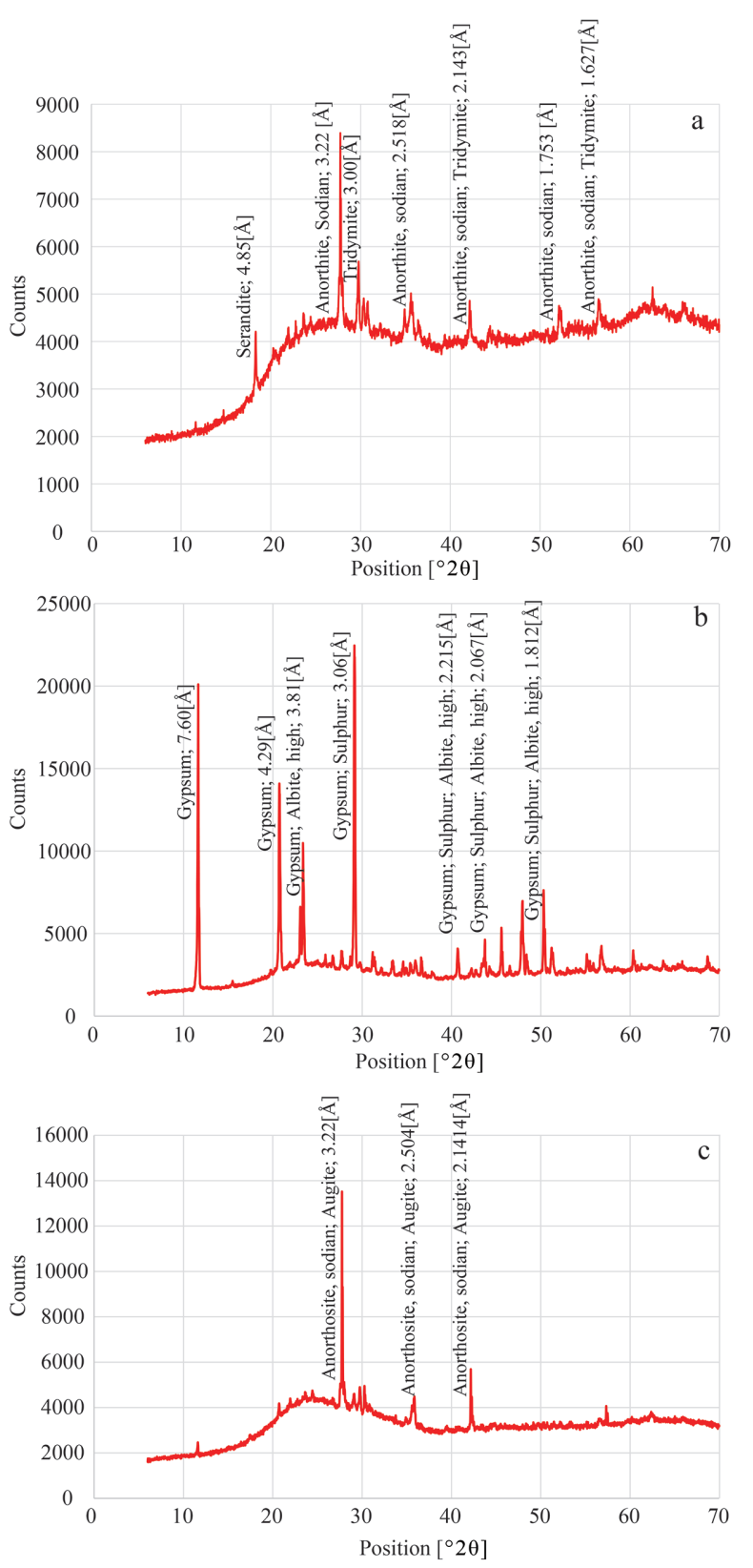

FIGURE 5. XRD patterns for the three samples that exhibited amorphous humps consistent with more Si-rich material than basaltic glass, (a) HI_15_MHY_002b, (b) HI_15_MHY_007b, and (c) HI_15 Solf_002_2. (Color online.)

Unfortunately, no fluid or gas measurements were available, and interpretation of the influence of changing gas composition cannot be determined at this time. The presence of sulfates could be due to a greater supply of sulfur near the vent, contributing to the formation of sulfates in the material closest to the vent or due to easier removal of mobile cations farther from the vent. The nature of the sample coating also appears to change with distance from the vent. Materials that exhibit leached surfaces are observed farther away from the vent (Group 1-1, 19.5-18.0 m, Figs. 1b-1c) and may represent passive silica enrichment from removal of other elements during weathering (e.g., Morris et al. 2008; Yen et al. 2008). Generally, thicker silica encrustations are observed on samples located closer to the vent (Groups 1-2, $1-3,1-4,2,3$, and 4, 11.5-4.0 m, Figs. 1d-1i) and may partially result from silica precipitated during low water-to-rock aqueous alteration of the basalts by acidic aerosols supplied by the vent (e.g., Ruff et al. 2011). Furthermore, the shift of the silica feature from 1115 to $1100 \mathrm{~cm}^{-1}$ observed in the Group 1-4 MIR spectra could be due to Al-substitution for Si. This could be expected in the samples observed here, as $\mathrm{Al}$ (along with $\mathrm{Si}$ and $\mathrm{Fe}^{3+}$ ) has increased solubility under acidic conditions (Hurowitz et al. 2006).

Many of the samples exhibited low abundances of Fe-oxides and sulfates in addition to silica in the chemical analyses (HI_15_MHY_002a, 003, 005, 006, 007a, and 007b, HI_15_Solf_003_3, Table 2). Although these low-abundance materials were not easily identifiable in many of the MIR signatures (Fig. 2) they were commonly distinguished in the VNIR range. The differences observed between the MIR and VNIR signatures are attributed to differences in mineral transparency between these two techniques and the nature of the alteration material. Some samples exhibit powdery surfaces that result in multiple surface scattering and reduced restrahlen features in the MIR (Hunt and Vincent 1968; Salisbury and Wald 1992; Mustard and Hays 1997), making it difficult to identify lower abundance phases. In addition, the fine grains and thin coatings that comprise the alteration material permit energy transmission through the grains/coatings (e.g., Hunt and Logan 1972; Clark and Roush 1984). This effect is enhanced in the VNIR due to the lower absorption coefficients in this range and increased importance of volume scattering (Salisbury and Wald 1992). This allows small abundance phases to be more easily detected in the VNIR and these may dominate the spectral properties.

The alteration phases observed here provide similar results to the previous works in Table 1. Here we observed MIR signatures dominated by silica and VNIR signatures influenced by silica, sulfate(s), and Fe-oxide(s). The phyllosilicate phases detected by Golden et al. (1993), Morris et al. (2000a), Schiffman et al. (2000), Bishop et al. (2007), and Hamilton et al. (2008) were only observed using linear least-squares modeling of the MIR data for Group 1-2 in abundances $\leq 10 \%$. Our results agree with the environmental conditions suggested by Schiffman et al. (2000), which attribute the development of opaline crusts to acidic conditions $(\mathrm{pH}<6)$ and clay mineral formation to more neutral conditions ( $\mathrm{pH}$ 6.5-7.8).

The global abundance and species of chemical alteration products on planetary surfaces are related to the starting composition of unaltered protolith, the style and duration of alteration processes, the fluid composition, the fluid-to-rock ratio (e.g., Tosca et al. 2004; Golden et al. 2005; Ming et al. 2006), and ultimately, to the preservation of those products in rocks and soils. Thus, detection and interpretation of alteration mineral assemblages is critical to deciphering the history of the Mars. However, amorphous material often forms as a product from the alteration of volcanic material and can cause difficulty in identifying additional alteration phases and obtaining quantitative abundances of alteration phases. Amorphous phases are an important component on Mars and have been observed in several occurrences by the Chemistry and Mineralogy Instrument 


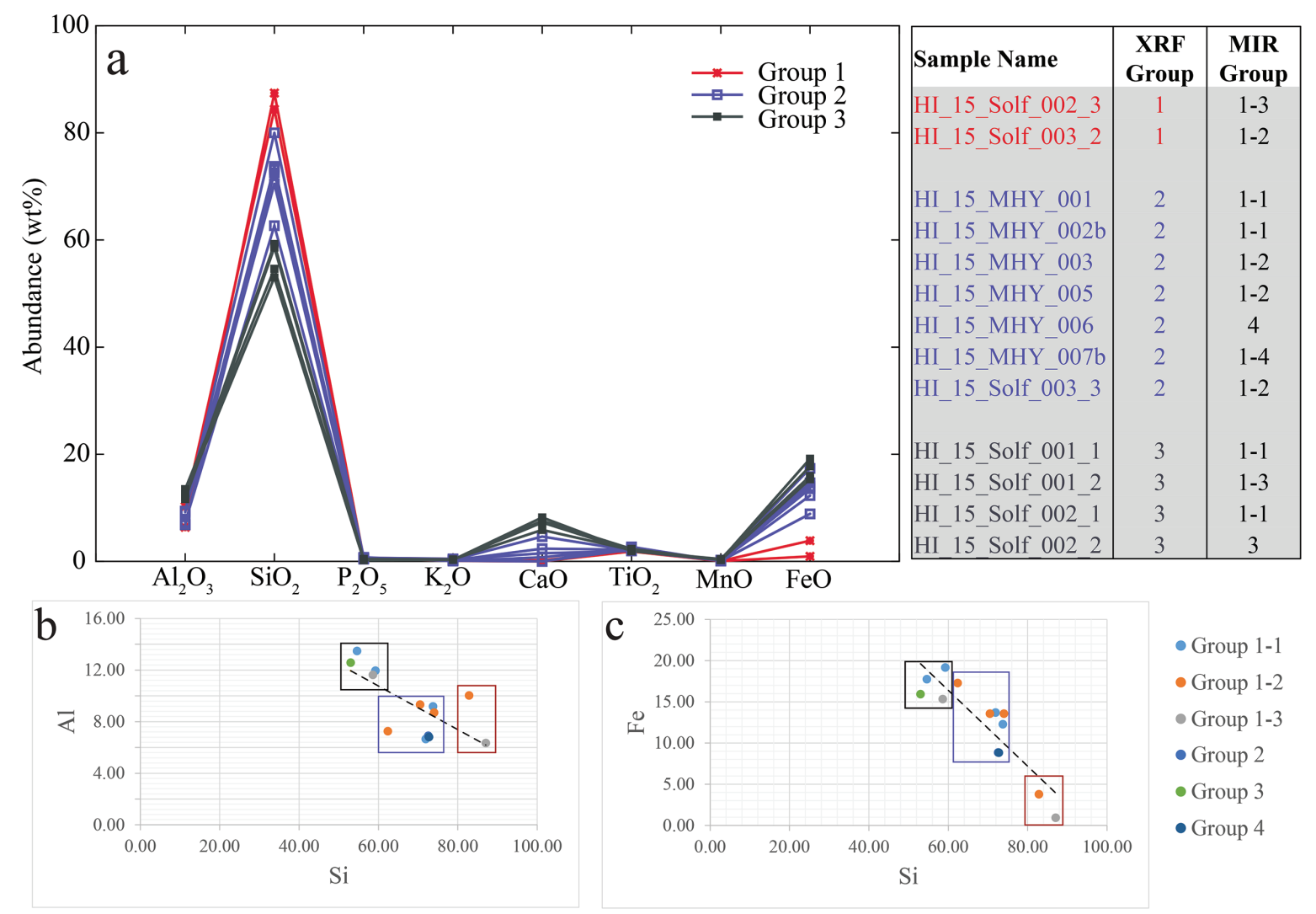

FIGURE 6. (a) Handheld XRF data separated into groups determined using a minimum distance clustering algorithm on chemical data for each sample. Plots of (b) Al vs. Si contents and (c) Fe vs. Si contents for the natural fumarolic materials. The outlined boxes represent the XRF groupings and the color of the points represent the MIR groupings. (Color online.)

(CheMin) onboard Curiosity (e.g., Bish et al. 2013). The presence of amorphous material was determined based on the appearance of a broad, diffuse peak than the narrow diagnostic peaks of well crystalline phases. This provides a challenge for identification because these phases lack long-range crystallographic order so analyses that depend on crystal structure (e.g., XRD) are non-unique. The fumarolic materials in this study may provide an analog for some of the amorphous phases on Mars, and the distinctive Si-rich features observed show that the addition of MIR/VNIR data helps to distinguish some of those materials.

\section{Hydrothermal alteration on Mars}

MIR and VNIR spectral analyses of hydrothermally altered Hawaiian basalts are presented here to enhance the understanding of the infrared spectral properties of weathered materials. The spectral shapes of the signatures acquired in this study can be applied to VNIR and MIR spectral data obtained from Mars to better constrain variability of weathering on a global scale. Based on our results, silica detections across both wavelength ranges are common from fumarolic alteration. However, we note that silica deposits are not limited to high-temperature and/or fumarolic processes (e.g., McLennan 2003; McAdam et al. 2008). For example, silica can form through acid fog weathering of basalt, with low water-to-rock ratios under near isochemical conditions (Tosca et al. 2004). Based on several chemical and mineralogical measurements made by landed missions (Clark 1993; Haskin et al. 2005; Ming et al. 2006; Clark et al. 2005; Morris et al. 2006), an acid fog environment has been proposed as a common and persistent alteration setting on the martian surface (Hurowitz and McLennan 2007; Hurowitz and Fischer 2014). Thus, it is useful to compare the spectral properties of silica-bearing samples from this fumarolic environment to those formed in a closed-system acid sulfate environment. Below, we compare the spectral characteristics of our samples to those from a previous study in which basaltic glass was subjected to lowtemperature, isochemical weathering under low water-to-rock ratios (Yant et al. 2016).

In a previous study, sand-sized synthetic martian glass particulates were submerged in sulfuric-hydrochloric acidic solutions ( $\mathrm{pH} \mathrm{0-4)}$ under low fluid-to-rock ratios (1:1) at ambient temperature and pressure (Yant et al. 2016). This system simulates an acid-fog environment that is considered closed due to the very low fluid-to-rock ratios. We use a laboratory environment because of the difficulty in determining how long a natural environment has been closed. In general, acid alteration on particles resulted in sulfate-dominated assemblages in the most acidic solutions $(\mathrm{pH} \leq 1)$ that exhibited well-developed sulfate features, in the MIR, and strong 1.45, 1.95, and 2.40 $\mu \mathrm{m}$ features in the VNIR. Amorphous silica was present based on chemical analyses, but not as detectable in the MIR/VNIR 
spectra. The results from Yant et al. (2016) contrast significantly with the silica-dominated assemblages observed for the majority of the samples in this study (Fig. 7).

The likely reason for the observed differences relates to open vs. closed system weathering. Sulfates, Fe-oxides, and silica are commonly identified as alteration products in martian analog studies (Table 1), and when present on the surface of substrates each contributes uniquely to the visual appearance and MIR/VNIR spectral signatures observed for these materials. In closed system weathering, as simulated by Yant et al. (2016), small volumes of acidic fluid react with the surface of the material resulting in a fluid enriched in the most soluble elements. A leached alteration rind, depleted in the most soluble elements, is left behind, and the fluid subsequently undergoes evaporation and deposits alteration minerals. $\mathrm{Si}^{4+}$ is relatively insoluble in low $\mathrm{pH}$ conditions $(\mathrm{pH}<2-3)$ and basaltic cations are relatively mobile (e.g., El-Shamy et al. 1972; Minitti et al. 2007). This can result in basalt leaching or dissolution that could form a silica-enriched layer beneath the fluid containing the mobile cations. When the fluid is evaporated, in a closed system, salts containing the more mobile cations can precipitate on top of the silica-enriched layer. The formation of the sulfates overlying the silica layer results in a larger spectral signal from the sulfates relative to the silica. To form a sulfate-dominated assemblage, the fluid-to-rock ratio needs to be small enough that the soluble elements are not mobilized and are allowed to precipitate on top of the leached surface in a closed system (Hurowitz et al. 2006). Additionally, sulfates that are precipitated over a diffuse area can be remobilized by dew and/or rain, whereas silica coatings are less soluble and less likely to be removed.

If the system is open and the fluid can migrate, a silica or
Fe-oxide-dominated assemblage can be formed (Dorn 2012; Chemtob and Rossman 2014). Chemtob and Rossman (2014) describe the formation of silica coatings on glassy basalts from Hawaii through reaction of acidic fluids in an open system using the following model. Fresh rock surfaces are wetted by rainwater or condensed water vapor. The fluid becomes acidified by volcanically derived liquids and reaction with this low $\mathrm{pH}$ fluid results in dissolution of the basalt. The basaltic cations are more soluble than the silica and the cations remain dissolved at low $\mathrm{pH}$ and the silica is precipitated in place. The fluid is mobilized carrying away the more soluble cations, leaving behind $\mathrm{Ti}$ and $\mathrm{Fe}^{3+}$, which have lower mobility and are deposited as Fe-Ti-oxides, in addition to the silica. Chemtob and Rossman (2014) suggest that this mobilization is facilitated by liquid water, possibly sourced from rainwater and condensed water vapor from nearby plumes. Silica can also be transported to the surface by fluids that penetrate to the interior of the basalt. As alteration continues over a period of years, episodes of dissolution-reprecipitation can result in the thickening of the silica layer and the remobilization of $\mathrm{Fe}$ and $\mathrm{Ti}$ to the surface, producing silica or Fe-oxide-dominated spectral signatures like those observed here. Additionally, Al behaves in a manner similar to $\mathrm{Fe}^{3+}$ and exhibits increased solubility in acidic conditions (Hurowitz et al. 2006) and could be expected to precipitate under the conditions shown here. Negative correlations were observed between $\mathrm{Fe}$ vs. $\mathrm{Si}$ and $\mathrm{Al}$ vs. $\mathrm{Si}$ in the $\mathrm{XRF}$ data (Fig. 6) supporting the interpretation that $\mathrm{Fe}$ and $\mathrm{Al}$ are both precipitating on top of the silica layers. The results shown here for the natural Hawaiian samples are in agreement with the model proposed by Chemtob and Rossman (2014).

Surfaces showing silica signatures in the VNIR and MIR provide the best candidates for potential fumarolic deposits. For
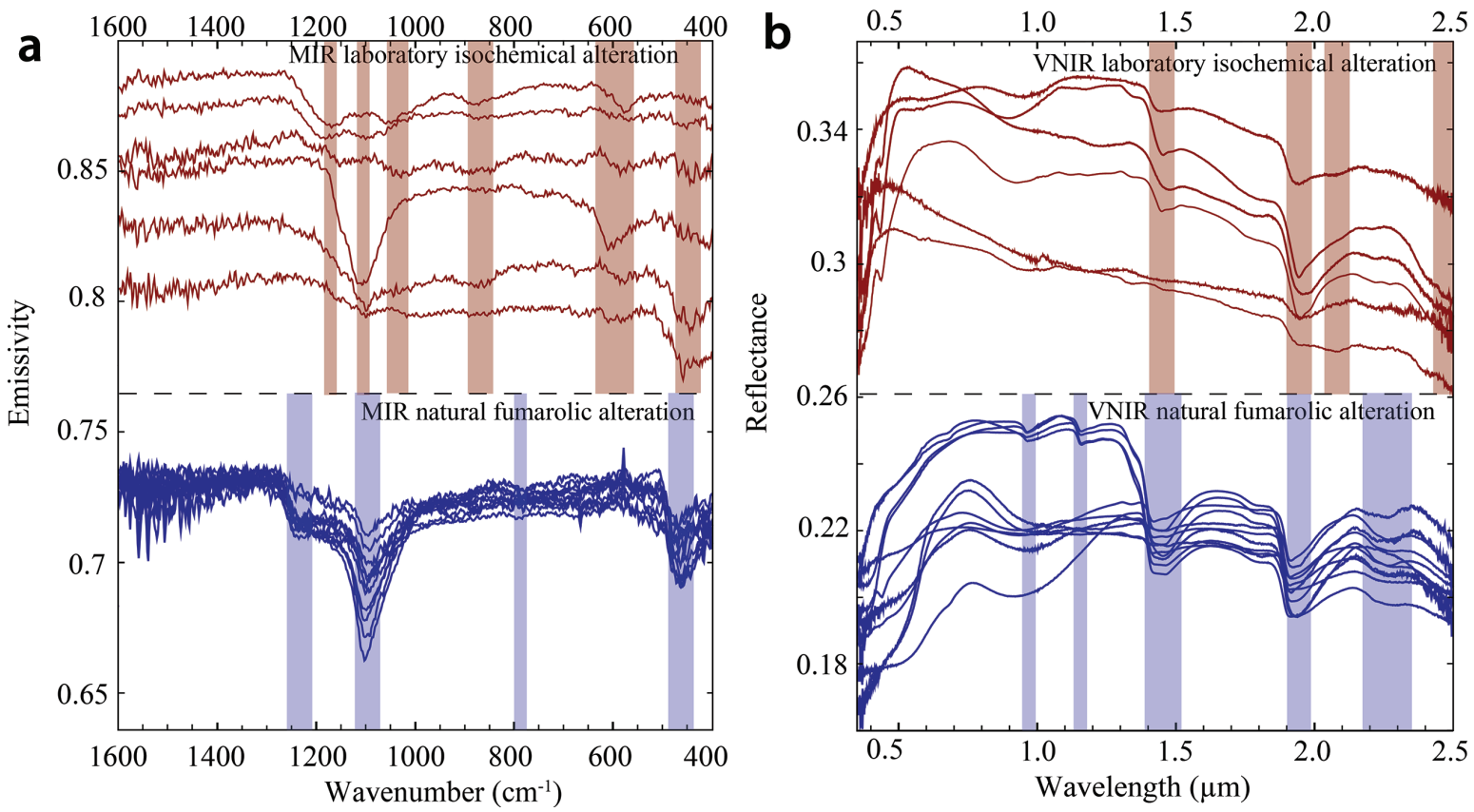

FIGURE 7. Comparison of the spectral signatures for the laboratory isochemically altered materials (sulfate-dominated) with the natural fumarolic altered materials (silica-dominated) in both the (a) MIR and (b) VNIR wavelength ranges. Red shaded areas correspond to sulfate-related features and blue shaded areas correspond to silica-related features. (Color online.) 
example, hydrated silica has been identified in several locations through VNIR detections from the Compact Reconnaissance Imaging Spectrometer for Mars (CRISM) at Western Hellas (Bandfield 2008), plains near Melas Chasma and Juventae Chasma (Milliken et al. 2008), Isidis Basin (Ehlmann et al. 2009), Northern Syrtis Major (Ehlmann et al. 2009; Smith and Bandfield 2012), Toro Crater (Marzo et al. 2010), Nili Patera (e.g., Skok et al. 2010), Terra Sirenum (Wray et al. 2011), and Noctis Labyrinthus (Weitz et al. 2011). Hydrated silica has also been identified in MIR data from the Thermal Emission Spectrometer (TES) and Thermal Emission Imaging System (THEMIS) at Western Hellas Basin (Bandfield 2008) and along the dichotomy boundary (Bandfield and Amador 2016). Hydrothermal processes have been inferred for most of these regions; however, it is difficult to rule out other origins from orbital data alone. Nevertheless, this work provides strong support for those interpretations.

\section{IMPLICATIONS}

This work provides a unique infrared spectral library that includes martian analog materials that were altered in an active terrestrial solfatara (hydrothermal) setting. Hydrothermal environments are of particular interest as they potentially indicate habitable conditions. Among the techniques to detect potential hydrothermal/habitable conditions on Mars, visible and infrared spectroscopic remote sensing provides the greatest coverage at the highest spatial resolution, allowing for assessment of spatial and/or temporal variability in surface conditions. Key constraints on the habitability and astrobiological potential of ancient aqueous environments are provided through detection and interpretation of secondary mineral assemblages; thus, spectral detection of fumarolic alteration assemblages observed from this study on Mars would suggest a region that could have hosted a habitable environment. Alteration assemblages that were potentially derived from hydrothermal systems have been detected in situ on Mars at Gusev Crater and Meridiani Planum. Kraft et al. (2003) suggest that secondary amorphous silica may account for the spectral signatures observed for ST2, exhibiting the potential widespread nature of this type of alteration. Using the spectral library provided here, the search for hydrothermal systems on Mars can be extended to other locations using orbital measurements of reflectance and emission spectra, which are sensitive to mineral species and abundance.

\section{ACKNOWLEDGMENTS}

All fieldwork reported here that was conducted within Hawai'i Volcanoes National Park (HVNP) was conducted under National Park Service (NPS) Scientific Research and Collection Permit HAVO-2012-SCI-0025 as part of NPS Study HAVO00420. This work was supported by the RIS4E node of NASA's Solar System Exploration Virtual Institute. A.D.R. also acknowledges support from the Mars Fundamental Research Program NNX13AG82G. The authors thank Steve Ruff for contributing silica reference spectra. NSF-EAR 0923224 awarded to Franklin and Marshall College facilitated a substantial upgrade of both XRD and XRF instrumentation. We also thank Joseph Michalski and Rebecca Greenberger for their insightful reviews. Last, S.A. Mertzman thanks Karen R. Mertzman for her ongoing meticulous work in the $\mathrm{X}$-ray lab without which there would be much less high-quality data in the world.

\section{REFERENCES CITED}

Anderson, J.H., and Wickersham, K.A. (1964) Near infrared characterization of water and hydroxyl groups on silica surfaces. Surface Science, 2, 251-260.

Arvidson, R.E., Squyres, S.W., Bell III, J.F., Catalano, J.G., Clark, B.C., Crumpler, L.S., de Souza Jr., P.A., Fairén, A.G., Farrand, W.H., Fox, V.K., and others. (2014) Ancient aqueous environments at Endeavour Crater, Mars. Science 343, 1248097, doi: 10.1126/science.1248097.
Baldridge, A.M. (2008) Thermal infrared spectral studies of sulfates and chlorides; applications to salts on the martian surface, 204 pp. Ph.D. dissertation thesis, Arizona State University, Tempe.

Baldridge, A.M., and Christensen, P.R. (2009) Laboratory technique for thermal emission measurement of hydrated minerals. Applied Spectroscopy, 63 , 678-688.

Bandfield, J.L. (2008) High-silica deposits of an aqueous origin in western Hellas Basin, Mars. Geophysical Research Letters, 35, 142-147, http://dx.doi. org/10.1029/2008GL033807.

Bandfield, J.L., and Amador, E.S. (2016) Extensive aqueous deposits at the base of the dichotomy boundary in Nilosyrtis Mensae, Mars, Icarus, 275, 29-44.

Bell, J. III (2008) The Martian Surface - Composition, Mineralogy, and Physical Properties. Cambridge University Press, New York.

Bigham, J.M., and Nordstrom, D.K. (2000) Iron and aluminum hydroxysulfates from acid sulfate waters. In C.N. Alpers, J.L. Jambor, and D.K. Nordstrom, Eds., Sulfate Minerals: Crystallography, Geochemistry and Environmental Significance, 40, pp. 351-404. Reviews in Mineralogy and Geochemistry, Mineralogical Society of America, Chantilly, Virginia.

Bish, D. L., Blake, D.F., Vaniman, D.T., Chipera, S.J., Morris, R.V., Ming, D.W., Treiman, A.H., Sarrazin, P., Morrison, S.M., Downs, R.T., Achilles, C.N., Yen, A.S., Bristow, T.F., Crisp, J.A., Morookian, J.M., Farmer, J.D., Rampe, E.B., Stolper, E.M., Spanovich, N., and MSL Science Team (2013) X-ray diffraction results from Mars Science Laboratory: Mineralogy of Rocknest at Gale Crater. Science, 341, 1238932.

Bishop, J.L., and Murad, E. (1996) Schwertmannite on Mars? Spectroscopic analyses of schwertmannite, its relationship to other ferric minerals, and its possible presence in the surface material on Mars. In M.D. Dyar et al., Eds., Mineral Spectroscopy: A Tribute to Roger G. Burns, 5, 337-358. Special Publication of the Geochemical Society.

Bishop, J.L., Schiffman, P., Lane, M.D., and Dyar, M.D. (2005a) Solfataric alteration in Hawaii as a mechanism for formation of the sulfates observed on Mars by OMEGA and the MER instruments. Lunar and Planetary Science Conference, XXVI, LPI, Houston, Abstract 1456.

Bishop, J.L., Dyar, M.D., Lane, M.D., and Bandfield, J.F. (2005b) Spectral identification of hydrated sulfates on Mars and comparison with acidic environments on Earth. International Journal of Astrobiology, 3, 275-285.

Bishop, J.L., Schiffman, P., Murad, E., Dyar, M.D., Drief, A., and Lane, M.D. (2007) Characterization of alteration products in tephra from Haleakala, Maui: a visible-infrared spectroscopy, Mössbauer spectroscopy, XRD, EMPA and TEM study. Clay Minerals, 55, 1-17.

Bishop, J.L., Noe Dobrea, E.Z., McKeown, N.K., Parente, M., Ehlmann, B.L., Michalski, J.R., Milliken, R.E., Poulet, F., Swayze, G.A., Mustard, J.F., Murchie, S.L., and Bibring, J.-P. (2008) Phyllosilicate diversity and past aqueous activity revealed at Mawrth Vallis, Mars. Science, 321, 830-833.

Bishop, J.L., Lane, M.D., Dyar, M.D., King, S.J., Brown, A.J., and Swayze, G. (2014) Spectral properties of Ca-sulfates: Gypsum, bassanite and anhydrite. American Mineralogist, 99, 2105-2115.

Bishop, J.L., Murad, E., and Dyar, M.D. (2015) Akaganéite and schwertmannite: Spectral properties and geochemical implications of their possible presence on Mars. American Mineralogist, 100, 738-746.

Burns, R.D., and Fisher, D.S. (1990) Iron-sulfur mineralogy of Mars: magmatic evolution and chemical weathering products. Journal of Geophysical Research, $95,14415-14421$.

Chemtob, S.M., and Rossman, G.R. (2014) Timescales and mechanisms of formation of amorphous silica coatings on fresh basalts at Kīlauea Volcano, Hawai'i. Journal of Volcanology and Geothermal Research, 286, 41-54.

Chemtob, S.M., Jolliff, B.L., Rossman, G.R., Eiler, J.M., and Arvidson, R.E. (2010) Silica coatings in the Ka'ū Desert, Hawaii, a Mars analog terrain: a micromorphological, spectral, chemical, and isotopic study. Journal of Geophysical Research, 115, E04001.

Christensen, P.R., Bandfield, J.L., Clark, R.N., Edgett, K.S., Hamilton, V.E., Hoefen, T., Kieffer, H.H., Kuzmin, R.O., Lane, M.D., Malin, M.C., and others. (2000) Detection of crystalline hematite mineralization on Mars by the Thermal Emission Spectrometer: Evidence for near-surface water. Journal of Geophysical Research, 105, 9623-9642.

Clark, B.C. (1993) Geochemical components in Martian soil. Geochimica et Cosmochimica Acta, 57, 4575-4581.

Clark, R.N., and Roush, T.L. (1984) Reflectance spectroscopy: Quantitative analysis techniques for remote sensing applications. Journal of Geophysical Research, 89(B7), 6329-6340, doi: 10.1029/JB089iB07p06329.

Clark, B.C., Morris, R.V., McLennan, S.M., Gellert, R., Jolliff, B., Knoll, A.H., Squyres, S.W., Lowenstein, T.K., Ming, D.W., Tosca, N.J., and others. (2005) Chemistry and mineralogy of outcrops at Meridiani Planum. Earth and Planetary Science Letters, 240, 73-94.

Cloutis, E.A., Hawthorne, F.C., Mertzman, S.A., Krenn, K., Craig, M.A., Marcino, D., Methot, M., Strong, J., Mustard, J.F., Blaney, D.L., Bell III, J.F., and Vilas, F. (2006) Detection and discrimination of sulfate minerals using reflectance spectroscopy. Icarus, 184, 121-157, doi: 10.1016/j.icarus.2006.04.003.

Costello, E.K., Halloy, S.R.P., Reed, S.C., Sowell, P., and Schmidt, S.K. (2009) Fumarole-supported islands of biodiversity within a hyperarid, high-elevation 
landscape on Socompa Volcano, Puna de Atacama, Andes. Applied Environmental Microbiology, 75, 735-747.

Crisp, J., Kahle, A.B., and Abbott, E.A. (1990) Thermal infrared spectral character of Hawaiian basaltic glasses. Journal of Geophysical Research, 95, 21657-21669.

Dorn, R.I. (2012) Formation of silica glaze rock coatings through water vapor interactions. Physical Geography, 33, 21-31.

Ehlmann, B.L., Mustard, J.F., Swayze, G.A., Clark, R.N., Bishop, J.L., Poulet, F., Des Marais, D.J., Roach, L.H., Milliken, R.E., Wray, J.J., Barnouin-Jha, O., and Murchie, S.L. (2009) Identification of hydrated silicate minerals on Mars using MRO-CRISM: Geologic context near Nili Fossae and implications for aqueous alteration. Journal of Geophysical Research, 114, E00D08, doi: 10.1029/2009JE003339.

El-Shamy, T.M., Lewins, J., and Douglas, R. W. (1972) The dependence of the pH on the decomposition of glasses by aqueous solutions. Journal of the Society of Glass Technology, 13(3), 81-87.

Ellis, D.G., Bizzoco, R.W., and Kelley, S.T. (2008) Halophilic Archaea determined from geothermal steam vent aerosols. Environmental Microbiology, $10,1582-1590$

Fischer, E.M., and Pieters, C.M. (1993) The continuum slope of Mars: bidirectional reflectance investigations and applications to Olympus Mons. Icarus, $102,185-202$.

Glotch, T.D., and Kraft, M.D. (2008) Thermal transformations of akaganéite and lepidocrocite to hematite: Assessment of possible precursors to Martian crystalline hematite. Physics and Chemistry of Minerals, 35, 569-581.

Glotch, T.D., Morris, R.V., Christensen, P.R., and Sharp, T.G. (2004) Effect of precursor mineralogy on the thermal infrared emission spectra of hematite: application to Martian hematite mineralization. Journal of Geophysical Research, 109.

Golden, D.C., Morris, R.V., Ming, D.W., Lauer, H.V. Jr., and Yang, S.R. (1993) Mineralogy of three slightly palagonitized basaltic tephra samples from the summit of Mauna Kea, Hawaii. Journal of Geophysical Research: Planets, 98, 3401-3411.

Golden, D.C., Ming, D.W., Morris, R.V., and Mertzman, S.A. (2005) Laboratorysimulated acid-sulfate weathering of basaltic materials: Implications for formation of sulfates at Meridiani Planum and Gusev crater, Mars. Journal of Geophysical Research, 110, E12S07.

Goryniuk, M.C., Rivard, B.A., and Jones, B. (2004) The reflectance spectra of opal-A $(0.5-25 \mu \mathrm{m})$ from the Taupo Volcanic Zone: Spectra that may identify hydrothermal systems on planetary surfaces. Geophysical Research Letters 31(24), doi: 10.1029/2004GL021481.

Halloy, S. (1991) Islands of life at $6000 \mathrm{~m}$ altitude - the environment of the highest autotrophic communities on Earth (Socompa Volcano, Andes). Arctic and Alpine Research, 23, 247-262.

Hamilton, V.E., Morris, R.V., Gruener, J.E., and Mertzman, S.A. (2008) Visible, near-infrared, and middle infrared spectroscopy of altered basaltic tephras: Spectral signatures of phyllosilicates, sulfates, and other aqueous alteration products with application to the mineralogy of the Columbia Hills of Gusev Crater, Mars. Journal of Geophysical Research: Planets, 113, E12S43.

Haskin, L.A., Wang, A., Jolliff, B.L., McSween, H.Y., Clark, B.C., Des Marais, D.J., McLennan, S.M., Tosca, N.J., Hurowitz, J.A., Farmer, J.D., and others. (2005) Water alteration of rocks and soils on Mars at the Spirit rover site in Gusev crater. Nature, 436, 66-69.

Horgan, B., and Bell, J.F. III (2012) Widespread weathered glass on the surface of Mars. Geology, 40(5), 391-394.

Hunt, G.R., and Logan, L.M. (1972) Variation of single particle mid-infrared emission spectrum with particle size. Applied Optics, 11, 142-147.

Hunt, G.R., and Vincent, R.K. (1968) The behavior of spectral features in the infrared emission from particulate surfaces of various grain sizes, Journal of Geophysical. Research, 73(18), 6039-6046, doi: 10.1029/JB073i018p06039.

Hurowitz, J.A., and Fischer, W.W. (2014) Contrasting styles of water-rock interaction 862 at the Mars Exploration Rover landing sites. Geochimica et Cosmochimica Acta, 127, 863, 25-38.

Hurowitz, J.A., and McLennan, S.M. (2007) A 3.5 Ga record of water-limited, acidic weathering conditions on Mars. Earth and Planetary Science Letters, 260, 432-443.

Hurowitz, J.A., McLennan, S.M., Tosca, N.J., Arvidson, R.E., Michalski, J.R., Ming, D.W., Schröder, C., and Squyres, S.W. (2006) In situ and experimental evidence for acidic weathering of rocks and soils on Mars. Journal of Geophysical Research, 111, E02S19.

Kraft, M.D., Michalski, J.R., and Sharp, T.G. (2003) Effects of pure silica coatings on thermal emission spectra of basaltic rocks: Considerations for Martian surface mineralogy. Geophysical Research Letters, 30, 2288.

Kraft, M.D., Sharp, T.G., Michalski, J.R., and Rampe, E.B. (2007) Combined thermal and near infrared spectra of hydrous silica coatings: Implications for surface Type 2 mineralogy and recent liquid water on Mars. Lunar and Planetary Science Conference XXXVIII.

Lane, M.D. (2007) Mid-infrared emission spectroscopy of sulfate and sulfatebearing minerals. American Mineralogist, 92, 1-18.

Lane, M.D., Bishop, J.L., Dyar, M.D., Hiroi, T.H., Mertzman, S.A., Bish, D.L.,
King, P.L., and Rogers, A.D. (2015) Mid-infrared emission spectroscopy and visible/near-infrared reflectance spectroscopy of Fe-sulfate minerals. American Mineralogist, 100, 66-82.

Lichtenberg, K.A., Arvidson, R.E., Morris, R.V., Murchie, S.L., Bishop, J.L., Remolar, D.F., Glotch, T.D., Dobrea, E.N., Mustard, J.F., Andrews-Hanna, J., and Roach, L.H. (2010) Stratigraphy of hydrated sulfates in the sedimentary deposits of Aram Chaos, Mars. Journal of Geophysical Research, 115, E00D17.

Madden, M.E., Bodnar, R.J., and Rimstidt, J.D. (2004) Jarosite as an indicator of water-limited chemical weathering on Mars. Nature, 431, 821-823.

Marzo, G.A., Davila, A.F., Tornabene, L.L., Dohm, J.M., Fairén, A.G., Gross, C., Kneissl, T., Bishop, J.L., Roush, T.L., and McKay, C.P. (2010) Evidence for Hesperian impact-induced hydrothermalism on Mars. Icarus, 208, 667-683.

McAdam, A.C., Zolotov, M.Y., Mironenko, M.V., and Sharp, T.G. (2008) Formation of silica by low-temperature acid alteration of Martian rocks: Physicalchemical constraints. Journal of Geophysical Research, 113, E08003, doi 10.1029/2007JE003056.

McCanta, M.C., Dyar, M.D., and Treiman, A.H. (2014) Alteration of Hawaiian basalts under sulfur-rich conditions: Applications to understanding surface-atmosphere interactions on Mars and Venus. American Mineralogist, 99, 291-302.

McCollom, T.M., and Hynek, B.M. (2005) A volcanic environment for bedrock diagenesis at Meridiani Planum, Mars. Nature, 438, 1129-1131.

McKeown, N.K., Bishop, J.L., Cuadros, J., Hillier, S., Amador, E., Makarewicz, H.D., Parente, M., and Silver, E.A. (2011) Interpretation of reflectance spectra of clay mineral-silica mixtures; implications for Martian clay mineralogy at Mawrth Vallis. Clays and Clay Minerals, 59, 400-415, doi: 10.1346 CCMN.2011.0590404.

McLennan, S.M. (2003) Sedimentary silica on Mars. Geology, 31, 315-318.

Michalski, J.R., Kraft, M.D., Sharp, T.G., and Christensen, P.R. (2006) Effects of chemical weathering on infrared spectra of Columbia River Basalt and spectral interpretations of martian alteration. Earth and Planetary Science Letters, 248, 822-829.

Milliken, R.E., Swayze, G.A., Arvidson, R.E., Bishop, J.L., Clark, R.N., Ehlmann, B.L., Green, R.O., Grotzinger, J.P., Morris, R.V., Murchie, S.L., and others (2008) Opaline silica in young deposits on Mars. Geology, 36, 847-850, doi: 10.1130/G24967A.1.

Ming, D.W., Mittlefehldt, D.W., Morris, R.V., Golden, D.C., Gellert, R., Yen, A., Clark, B.C., Squyres, S.W., Farrand, W.H., Ruff, S.W., and others. (2006) Geochemical and mineralogical indicators for aqueous processes in the Columbia Hills of Gusev crater, Mars. Journal of Geophysical Research, 111, E02S12.

Minitti, M.E., Weitz, C.M., Lane, M.D., and Bishop, J.L. (2007) Morphology, chemistry, and spectral properties of Hawaiian rock coatings and implications for Mars. Journal of Geophysical Research, 112, E05015, doi: 10.1029/2006JE002839.

Morris, R.V., Lauer, H.V. Jr., Lawson, C.A., Gibson, E.K. Jr., Nace, G.A., and Stewart, C. (1985) Spectral and other physicochemical properties of submicron powders of hematite $\left(\alpha-\mathrm{Fe}_{2} \mathrm{O}_{3}\right)$, maghemite $\left(\gamma-\mathrm{Fe}_{2} \mathrm{O}_{3}\right)$, magnetite $\left(\mathrm{Fe}_{3} \mathrm{O}_{4}\right)$, goethite $(\alpha-\mathrm{FeOOH})$, and lepidocrocite $(\gamma$-FeOOH$)$. Journal of Geophysical Research, 90, 3126-3144.

Morris, R.V., Golden, D.C., Bell, J.F. III, Shelfer, T.D., Scheinost, A.C., Hinman, N.W., Furniss, G., Mertzman, S.A., Bishop, J.L., Ming, D.W., Allen, C.C., and Britt, D.T. (2000a) Mineralogy, composition and alteration of Mars Pathfinder rocks and soils: Evidence from multispectral, elemental and magnetic data on terrestrial analogue, SNC meteorite and Pathfinder samples. Journal of Geophysical Research, 105, 1757-1817.

Morris, R.V., Graff, T., Lane, M.D., Golden, D.C., Schwandt, C.S., Ming, D.W., Shelfer, T.D., Mertzman, S.A., Bell, J.F., Crisp, J., and Christensen, P.R. (2000b) Acid sulfate alteration products of a tholeiitic basalt: Implications for interpretation of Martian thermal emission spectra. Lunar and Planetary Science Conference, XXXI, Abstract 2014.

Morris, R.V., Ming, D.W., Graff, T.G., Arvidson, R.E., Bell, J.F. III, Squyres, S.W. Mertzman, S.A., Gruener, J.E., Golden, D.C., Le, L., and Robinson, G.A. (2005) Hematite spherules in basaltic tephra altered under aqueous, acid-sulfate conditions on Mauna Kea volcano, Hawaii: Possible clues for the occurrence of hematite-rich spherules in the Burns formation at Meridiani Planum, Mars. Earth and Planetary Science Letters, 240, 168-178.

Morris, R.V., Klingelhöfer, G., Schröder, C., Rodionov, D.S., Yen, A., Ming, D.W., de Souza, P.A. Jr., Fleischer, I., Wdowiak, T., Gellert, R., Bernhardt, B., and others. (2006) Mössbauer mineralogy of rock, soil, and dust at Gusev crater, Mars: Spirit's journey through weakly altered olivine basalt on the plains and pervasively altered basalt in the Columbia Hills. Journal of Geophysical Research, 111, E02S13.

Morris, R.V., Ming, D.W., Gellert, R., Yen, A., Clark, B.C., Graff, T.G., Arvidson, R.E., Squyres, S.W., and the Athena and CRISM Science Teams (2008) The hydrothermal system at Home Plate in Gusev crater, Mars: Formation of high silica material by acid-sulfate alteration of basalt. Lunar and Planetary Science Conference, XXIX, Abstract 2208.

Morris, R.V., Rampe, E.B., Graff, T.G., Archer, P.D. Jr., Le, L., Ming, D.W., and Sutter, B. (2015) Transmission X-ray diffraction (XRD) patterns relevant to the MSL CheMin amorphous component: sulfates and silicates. Lunar and Planetary Science Conference, XXVI, Abstract 2434. 
Mustard, J.F., and Hays, J.E. (1997) Effects of hyperfine particles on reflectance spectra from 0.3 to $25 \mu \mathrm{m}$. Icarus, $125,145-163$.

Niles, P.B., and Michalski, J. (2009) Meridiani Planum sediments on Mars formed through weathering in massive ice deposits. Nature Geoscience, 2, 215-220.

Rampe, E.B., Kraft, M.D., and Sharp, T.G. (2009) Chemical weathering trends from TIR spectral models: Implications for deriving weathering trends from martian spectral data. Lunar and Planetary Science Conference XL, 2132

Ramsey, M.S., and Christensen, P.R. (1998) Mineral abundance determination: Quantitative deconvolution of thermal emission spectra. Journal of Geophysical Research, 103(B1), 577-597.

Rice, M.S., Cloutis, E.A., Bell, J.F. III, Bish, D.L., Horgan, B.H., Mertzman, S.A., Craig, M.A., Renaut, R.W., Gautason, B., and Mountain, B. (2013) Reflectance spectra diversity of silica-rich materials: Sensitivity to environment and implications for detections on Mars. Icarus, 223(1), 499-533, doi: 10.1016/j.icarus.2012.09.021.

Rogers, A.D., and Aharonson, O. (2008) Mineralogical composition of sands in Meridiani Planum determined from MER data and comparison to orbital measurements. Journal of Geophysical Research: Planets, 113, E06S14.

Ruff, S.W., Christensen, P.R., Barbera, P.W., and Anderson, D.L. (1997) Quantitative thermal emission spectroscopy of minerals: A laboratory technique for measurement and calibration. Journal of Geophysical Research, 102, 14899-14913, doi: 10.1029/97JB00593.

Ruff, S.W., Farmer, J.D., Calvin, W.M., Herkenhoff, K.E., Johnson, J.R., Morris, R.V., Rice, M.S., Arvidson, R.E., Bell, J.F. III, Christensen, P.R., and Squyres, S.W. (2011) Characteristics, distribution, origin, and significance of opaline silica observed by the Spirit rover in Gusev crater, Mars. Journal of Geophysical Research, 116, E00F23.

Salisbury, J.W., and Wald, A. (1992) The role of volume scattering in reducing spectral contrast of Restrahlen bands in spectra of powdered minerals. Icarus, $96,121-128$.

Schiffman, P., Spero, H.J., Southard, R.J., and Swanson, D.A. (2000) Controls on palagonitization versus pedogenic weathering of basaltic tephra: Evidence from the consolidation and geochemistry of the Keanakako'i Ash Member, Kilauea Volcano. Geochemistry, Geophysics, Geosystems, 1, 1040

Schiffman, P., Zierenberg, R., Marks, N., Bishop, J.L., and Dyar, M.D. (2006) Acidfog deposition at Kilauea volcano: A possible mechanism for the formation of siliceous-sulfate rock coatings on Mars. Geology, 34, 921-924.

Schmidt, M.E., Ruff, S.W., McCoy, T.J., Farrand, W.H., Johnson, J.R., Gellert, Ralf, Ming, D.W., Morris, R.V., Cabrol, N., Lewis, K.W., and Schroeder, C. (2008) Hydrothermal origin of halogens at Home Plate, Gusev Crater. Journal of Geophysical Research, 113, E06S12.

Seelos, K.D., Arvidson, R.E., Jolliff, B.L., Chemtob, S.M., Morris, R.V., Ming, D.W., and Swayze, G.A., (2010) Silica in a Mars analog environment: Ka'ū Desert, Kilauea Volcano, Hawaii. Journal of Geophysical Research, 115, E00D15, doi: 10.1029/2009JE003347.

Sklute, E. (2015) On the subject of analyzing iron and sulfur bearing minerals from three extreme environments: Geological carbon sequestration, acid mine drainage, and Mars. Ph.D. dissertation thesis, 433 pp., Stony Brook University, New York

Skok, J.R., Mustard, J.F., Ehlmann, B.L., Milliken, R.E., and Murchie, S.L. (2010) Silica deposits in the Nili Patera caldera on the Syrtis Major volcanic complex on Mars. Nature Geoscience, 3, 838-841.

Smith, M.R., and Bandfield, J.L. (2012) Geology of quartz and hydrated silicabearing deposits near Antoniadi Crater, Mars. Journal of Geophysical Research, 117, E06007, doi: 10.1029/2011JE004038.

Squyres, S., McCoy, T. McEwen, A.S., McSween, H.Y., Ming, D.W., Moore, J.M.,
Morris, R.V., Parker, T.J., Rice, J.W. Jr., Ruff, S., and others. (2007) Pyroclastic activity at Home Plate in Gusev Crater, Mars. Science, 316, 738-742.

Squyres, S.W., Arvidson, R.E., Bell, J.F. III, Calef, F. III, Clark, B.C., Cohen, B.A., Crumpler, L.A., de Souza, P.A. Jr., Farrand, W.H., Gellert, R., and others. (2012) Ancient impact and aqueous processes and Endeavour Crater, Mars. Science, 336, 570-576, doi: 10.1126/science.1220476.

Tosca, N.J., McLennan, S.M., Lindsley, D.H., and Schoonen, M.A.A. (2004) Acidsulfate weathering of synthetic Martian basalt: The acid fog model revisited. Journal of Geophysical Research, 109, E05003.

Weitz, C.M., Bishop, J.L., Thollot, P., Mangold, N., and Roach, L.H. (2011) Diverse mineralogies in two troughs of Noctis Labyrinthus. Geology, 39, 899-902, doi: $10.1130 / \mathrm{G} 32045.1$

Wray, J.J., Milliken, R.E., Dundas, C.M., Swayze, G.A., Andrews-Hanna, J.C., Baldridge, A.M., Chojnacki, M., Bishop, J.L., Ehlmann, B.L., Murchie, S.L., and others. (2011) Columbus crater and other possible groundwater-fed paleolakes of Terra Sirenum, Mars. Journal of Geophysical Research, 116, E01001, doi: 10.1029/2010JE003694

Wyatt, M.B., Hamilton, V., McSween, H.Y. Jr., Christensen, P.R., and Taylor, L.A (2001) Analysis of terrestrial and Martian volcanic compositions using thermal emission spectroscopy: 1. Determination of mineralogy, chemistry, and classification strategies. Journal of Geophysical Research, 106(E7), 14711-14732.

Yant, M., Rogers, A.D., Nekvasil, H., Zhao, Y.-Y.S., and Bristow, T. (2016) Spectra characterization of acid weathering products on Martian basaltic glass. Journal of Geophysical Research: Planets, 121, doi: 10.1002/2015JE004969.

Yen, A.S., Morris, R.V., Clark, B.C., Gellert, R., Knudson, A.T., Squyres, S., Mittlefehldt, D.W., Ming, D.W., Arvidson, R., McCoy, T., and others. (2008) Hydrothermal processes at Gusev Crater: An evaluation of Paso Robles class soils Journal of Geophysical Research, 113, E06S10, doi: 10.1029/2007JE002978.

Young, K.E., Evans, C.A., and Hodges, K.V. (2011) Laboratory tests of a handheld $\mathrm{X}$-ray fluorescence spectrometer: A tool for planetary exploration. American Geophysical Union, Fall Meeting, Abstract P43B-1672.

(2012) Evaluating handheld X-ray fluorescence (XRF) technology in planetary exploration: Demonstrating instrument stability and understanding analytical constraints and limits for basaltic rocks. Lunar and Planetary Science Conference, XLIII, Abstract 2628.

Young, K.E., Bleacher, J.., Evans, C.A., Rogers, A.D., Ito, G., Arzoumanian, Z and Gendreau, K. (2015) Examining volcanic terrains using in situ geochemical technologies: Implications for planetary field geology. Lunar and Planetary Science Conference, XLVI, Abstract 1658.

Young, K.E., Evans, C.A., Hodges, K.V., Bleacher, J.E., and Graff, T.G. (2016) A review of the handheld X-ray fluorescence spectrometer as a tool for field geologic investigations on Earth and in planetary surface exploration. Applied Geochemistry, 72, 77-87, doi: 10.1016/j.apgeochem.2016.07.003.

MANUSCRIPT RECEIVED FEBRUARY 24, 2017

MANUSCRIPT ACCEPTED AUGUST 30, 2017

MANUSCRIPT HANDLED BY JAVIER CUADROS

\section{Endnote:}

'Deposit item AM-18-16116, Supplemental Table. Deposit items are free to all readers and found on the MSA web site, via the specific issue's Table of Contents (go to http://www.minsocam.org/MSA/AmMin/TOC/2018/Jan2018_data/ Jan2018 data.html). 